\title{
Effects of a low-carbohydrate diet on glycemic control in outpatients with severe type 2 diabetes Hajime Haimoto*1, Tae Sasakabe ${ }^{2}$, Kenji Wakai ${ }^{3}$ and Hiroyuki Umegaki ${ }^{4}$
}

Address: ${ }^{1}$ Department of Internal Medicine, Haimoto Clinic, 1-80 Yayoi, Kasugai, Aichi 486-0838, Japan, ${ }^{2}$ Department of Clinical Nutrition, Haimoto Clinic, 1-80 Yayoi, Kasugai, Aichi 486-0838, Japan, ${ }^{3}$ Department of Preventive Medicine/Biostatistics and Medical Decision Making, 65 Tsuruma, Showa, Nagoya, Aichi 466-8550, Japan and ${ }^{4}$ Department of Geriatrics, Nagoya University Graduate School of Medicine, 65 Tsuruma, Showa, Nagoya, Aichi 466-8550, Japan

Email: Hajime Haimoto* - haimoto@gol.com; Tae Sasakabe - haiclipar-mail78@gol.com; Kenji Wakai - wakai@med.nagoya-u.ac.jp; Hiroyuki Umegaki - umegaki@med.nagoya-u.ac.jp

* Corresponding author

Published: 6 May 2009

Nutrition \& Metabolism 2009, 6:21 doi:10.1186/1743-7075-6-21
Received: 21 December 2008

Accepted: 6 May 2009

This article is available from: http://www.nutritionandmetabolism.com/content/6/I/2।

(c) 2009 Haimoto et al; licensee BioMed Central Ltd.

This is an Open Access article distributed under the terms of the Creative Commons Attribution License (http://creativecommons.org/licenses/by/2.0), which permits unrestricted use, distribution, and reproduction in any medium, provided the original work is properly cited.

\begin{abstract}
We previously demonstrated that a loosely restricted $45 \%$-carbohydrate diet led to greater reduction in hemoglobin $\mathrm{Alc}(\mathrm{HbAlc})$ compared to high-carbohydrate diets in outpatients with mild type 2 diabetes (mean $\mathrm{HbAlc}$ level: 7.4\%) over 2 years. To determine whether good glycemic control can be achieved with a 30\%-carbohydrate diet in severe type 2 diabetes, 33 outpatients ( 15 males, 18 females, mean age: $59 \mathrm{yrs}$ ) with $\mathrm{HbAlc}$ levels of $9.0 \%$ or above were instructed to follow a low-carbohydrate diet ( $1852 \mathrm{kcal}$; \%CHO:fat:protein $=30: 44: 20)$ for 6 months in an outpatient clinic and were followed to assess their $\mathrm{HbAlc}$ levels, body mass index and doses of antidiabetic drugs. HbAlc levels decreased sharply from a baseline of $10.9 \pm 1.6 \%$ to $7.8 \pm 1.5 \%$ at 3 months and to $7.4 \pm 1.4 \%$ at 6 months. Body mass index decreased slightly from baseline $(23.8 \pm 3.3)$ to 6 months $(23.5 \pm 3.4)$. Only two patients dropped out. No adverse effects were observed except for mild constipation. The number of patients on sulfonylureas decreased from 7 at baseline to 2 at 6 months. No patient required inpatient care or insulin therapy. In summary, the $30 \%$-carbohydrate diet over 6 months led to a remarkable reduction in HbAlc levels, even among outpatients with severe type 2 diabetes, without any insulin therapy, hospital care or increase in sulfonylureas. The effectiveness of the diet may be comparable to that of insulin therapy.
\end{abstract}

\section{Background}

Carbohydrate-restricted diets (CRDs) have been reported to be effective for glycemic control [1-7] in type 2 diabetes (T2DM). We recently demonstrated that a loosely restricted 45\%-carbohydrate diet (carbohydrate-reduced diet: CRD) led to a significant reduction in hemoglobin A1c (HbA1c) levels with a tapering off of sulfonylureas compared to a $60 \%$-carbohydrate diet (high-carbohydrate diet: HCD) over 2 years among outpatients with mild T2DM (mean HbA1c $=7.4 \%$ ) [8].
Little is known about the long-term effects of CRDs on patients with severe T2DM. We therefore tried to determine whether good glycemic control can be achieved with a stricter CRD (30\%-carbohydrate), even in outpatients with severe T2DM in an outpatient clinic.

\section{Patients and methods}

We recruited outpatients with T2DM having HbA1c levels of $9.0 \%$ or above between September 2005 and September 2007 in Haimoto Clinic, and followed their HbA1c 
levels, body mass index (BMI) and doses of antidiabetic drugs monthly for 6 months. We also followed their serum lipid profiles, serum creatinine and blood pressure. Patients with serum creatinine levels $>1.5 \mathrm{mg} / \mathrm{dl}$, severe diabetes complications (proliferative retinopathy, symptomatic neuropathy and diabetic foot), ketoacidosis, soft drink ketosis [9] and malignant tumor were excluded. Five patients who developed ketosis received fluid therapy for a few days, and did not require any inpatient care or insulin therapy. We intended to taper the dose of sulfonylureas as soon as the patients' HbA1c levels were controlled, and to prescribe metformin, acarbose and pioglitazone. The patients were instructed to maintain their usual level of physical activity throughout the study. Changes in activity levels were investigated by questionnaire. The study protocol was identical to that of the previous study [8] and was approved by the Ethical Committee of the Nagoya Tokusyukai General Hospital. All patients provided written informed consent.

The main principle of the CRD was to eliminate carbohydrate-rich food twice a day at breakfast and dinner, or eliminate it three times a day at breakfast, lunch and dinner. Table 1 shows the list of foods that the subjects were instructed to avoid. There were no other restrictions. Patients on the CRD were permitted to eat as much protein and fat as they wanted, including saturated fat. Their details were described previously [8]. At the end of the study, dietary intake was assessed based on 3-day food records. Changes in HbA1c and BMI were assessed by the Friedman test, and changes in serum LDL-cholesterol, HDL-cholesterol, triglyceride, creatinine and blood pressure were assessed by the paired $t$-test.

\section{Results}

Thirty-three patients participated in this study. Background characteristics of the patients are shown in Table 2 . Two patients $(6 \%)$ on the CRD dropped out after 4 months. Of the remaining 31 patients, the total energy intake (mean $\pm \mathrm{SD}$ ) was $1852 \pm 549 \mathrm{kcal} /$ day (Table 3$)$. The daily average intakes of carbohydrate, fat and protein were $137 \pm 41 \mathrm{~g}(30 \pm 10 \%$ of total energy), $91 \pm 34 \mathrm{~g}$ ( 44 $\pm 10 \%)$ and $91 \pm 30 \mathrm{~g}(20 \pm 4 \%)$, respectively, with the mean fiber intake being $14 \pm 6 \mathrm{~g}$. The carbohydrates were mainly derived from rice and noodles made from wheat or buckwheat, and also from potatoes, fruits, bread and confectioneries.

The mean HbA1c level decreased sharply from baseline $(10.9 \pm 1.6 \%)$ to $7.8 \pm 1.5 \%$ at 3 months, and then more gradually to $7.4 \pm 1.4 \%$ at 6 months $(P<0.001)$ (Table 4 and Figure 1). BMI slightly decreased over 6 months, but the decrease did not reach statistical significance $(P=$ 0.057) (Table 4 and Figure 2). HbA1c levels of the two drop-out patients were $13.0 \%$ and $9.5 \%$ at baseline, which decreased to $8.6 \%$ and $8.1 \%$ after 3 months but returned to $12.6 \%$ and $8.6 \%$ after 6 months, respectively. When the two patients were excluded, the mean HbA1c level after 6 months was $7.2 \pm 1.0 \%$. No adverse effect was observed except for mild constipation. One female patient had an increased physical activity level during the study period in spite of our instructions. However, her increase in physical activity was no more than one hour of walking per day, four days a week. She had implemented an 11\%carbohydrate diet without any antidiabetic drug, and her HbA1c level decreased from $14.4 \%$ at baseline to $6.1 \%$ after 3 months and had been maintained at 5.5\% after 6 months.

Ten patients had already been prescribed antidiabetic drugs by other physicians at baseline. The number of patients who were on sulfonylureas decreased over 6 months (glibenclamide: from 6 to 1 , glimepiride: from 1 to 0 , tolbutamide: from 0 to 1 ) (Table 4). Of the 31 patients, 12 received other antidiabetic drugs at the end of the study; a relatively low dose of metoformin or miglitol was mainly prescribed. No patient required inpatient care or insulin therapy.

Excluding 4 patients who were prescribed the lipid-lowering drugs during the study period, the mean serum LDLcholesterol levels of the subjects decreased $(P=0.036)$ (Table 4 and Figure 3), while their mean HDL-cholesterol levels increased $(P=0.008)$ over 6 months (Table 4 and Figure 4). The mean serum triglyceride concentrations decreased over 6 months, but the change did not reach statistical significance $(P=0.39)$ (Table 4$)$. We found no significant change in serum creatinine. Eleven patients were prescribed antihypertensive drugs during the study period. No significant change was detected in systolic and diastolic blood pressure.

Table I: Carbohydrate-rich foods instructed to remove in the carbohydrate-reduced diet

\begin{tabular}{|c|c|}
\hline Staple foods & rice, bread, corn, spaghetti, noodle made of wheat or buckwheat, potato, sweet potato, taro and yam \\
\hline Fruits & $\begin{array}{l}\text { pear, apple, persimmon, mikan, orange, grapefruit, peach, grape, melon, water melon, banana, pine apple and Japanese chestnut, } \\
\text { etc. }\end{array}$ \\
\hline Vegetables & carrot, Indian lotus, pumpkin and autumn squash \\
\hline \multicolumn{2}{|c|}{ Confectioneries } \\
\hline Drink & beverages containing sugar, glucose and fructose, and milk \\
\hline Alcohol & brew: sake, beer and wine (Distilled liquor was not restricted.) \\
\hline
\end{tabular}


Table 2: Background characteristics in all patients $(n=33)$

\begin{tabular}{lc}
\hline Age (years) & $59 \pm 9$ \\
Male/Female (n) & $15 / 18$ \\
Duration of diabetes (months) & $59 \pm 9$ \\
Body weight $(\mathrm{kg})$ & $60.9 \pm 11.0$ \\
Body mass index & $23.8 \pm 3.3$ \\
Hemoglobin Alc $(\%)$ & $10.9 \pm 1.6$ \\
Serum LDL-cholesterol (mg/dl) & $147 \pm 50$ \\
Serum HDL-cholesterol (mg/dl) & $51 \pm 14$ \\
Serum triglyceride (mg/dl) & $187 \pm 177$ \\
Serum creatinine (mg/dl) & $0.68 \pm 0.20$ \\
Systolic blood pressure (mmHg) & $138 \pm 17$ \\
Diastolic blood pressure $(\mathrm{mmHg})$ & $81 \pm 11$ \\
Patients with medications $(\mathrm{n})$ & \\
$\quad$ Antidiabetic drugs & 10 \\
Antihypertensive drugs & 11 \\
$\quad$ Lipid-lowering drugs & 4 \\
\hline
\end{tabular}

Plus-minus values indicate means $\pm S D$

\section{Discussion}

This study demonstrated that good glycemic control with a tapering off of sulfonylureas and improvement of the serum cholesterol profile can be achieved with a 30\%-carbohydrate diet among outpatients with severe T2DM at an outpatient clinic. The mean HbA1c level decreased by $1.0 \%$ per month during the first 3 months. Our results must be cautiously interpreted due to the lack of a control group. However, it can be difficult to decrease HbA1c by $3.5 \%$ by means of HCDs over 6 months without any inpatient care, insulin therapy or reinforcement of sulfonylureas. When HCDs were incorporated into the dietary therapy for severe T2DM, the expected decreases in HbA1c levels for the insulin therapy ranged from $1.5 \%$ to $2.5 \%$, while that for oral sulfonylureas was about $1.5 \%$ in T2DM [10]. Moreover, practitioners in Japan have achieved HbA1c levels ranging from 7.6 to $7.7 \%$ by means of insu-

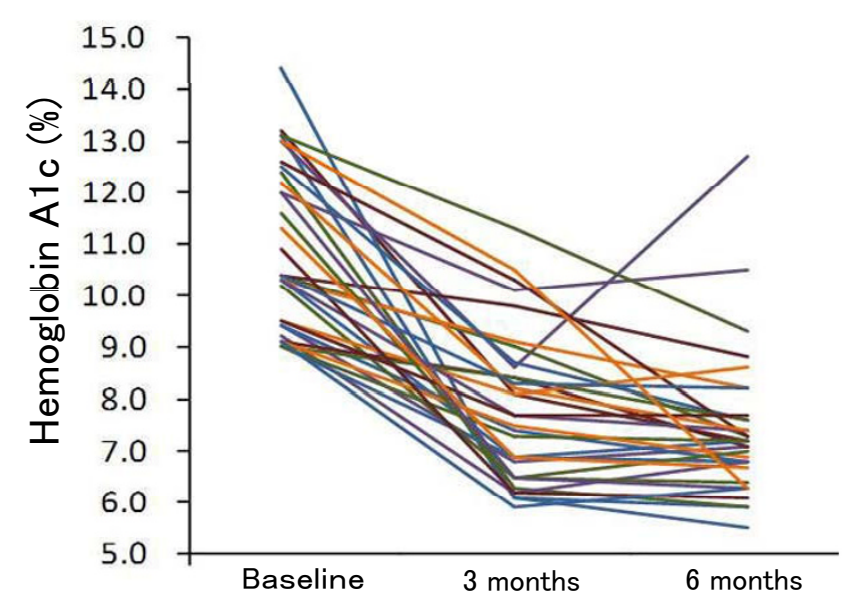

Figure I

Individual changes in hemoglobin A I c over 6 months $(\mathbf{n}=33)$. Two drop-out patients were included.
Table 3: Daily dietary intake at 6 months from baseline $(n=3 I)$

\begin{tabular}{lc}
\hline Total energy intake (kcal) & $1852 \pm 549$ \\
Carbohydrate $(\mathrm{g})$ & $137 \pm 41$ \\
Fiber $(\mathrm{g})$ & $14 \pm 6$ \\
Carbohydrate (\% energy) & $30 \pm 10$ \\
Fat (g) & $91 \pm 34$ \\
Saturated fat (g) & $26 \pm 13$ \\
Monounsaturated fat (g) & $35 \pm 16$ \\
Polyunsaturated fat (g) & $17 \pm 7$ \\
Fat (\% energy) & $44 \pm 10$ \\
Protein (g) & $91 \pm 30$ \\
Protein (\% energy) & $20 \pm 4$ \\
Foods rich in carbohydrate (g) & \\
$\quad$ Rice & $132 \pm 86$ \\
$\quad$ Noodles & $25 \pm 43$ \\
Bread & $15 \pm 29$ \\
Potatoes & $11 \pm 18$ \\
Fruit & $39 \pm 54$ \\
Confectioneries & $12 \pm 20$ \\
Sugar & $7 \pm 6$ \\
\hline
\end{tabular}

Plus-minus values indicate means $\pm \mathrm{SD}$.

Two drop-out patients are excluded.

lin treatment or insulin plus oral antidiabetic drugs among patients with severe T2DM [11]. Thus, the effectiveness of the 30\%-carbohydrate diet could be compared to that of the insulin therapy with HCDs, so that CRD can be considered an alternative to conventional HCDs in the dietary management of T2DM.

When total energy intake is strictly restricted, there may be little difference in glycemic control between CRDs and HCDs [12]. In contrast, CRD has the advantage that is does not restrict fat and protein and does not require explicit attention to total energy intake [8], giving rise to a

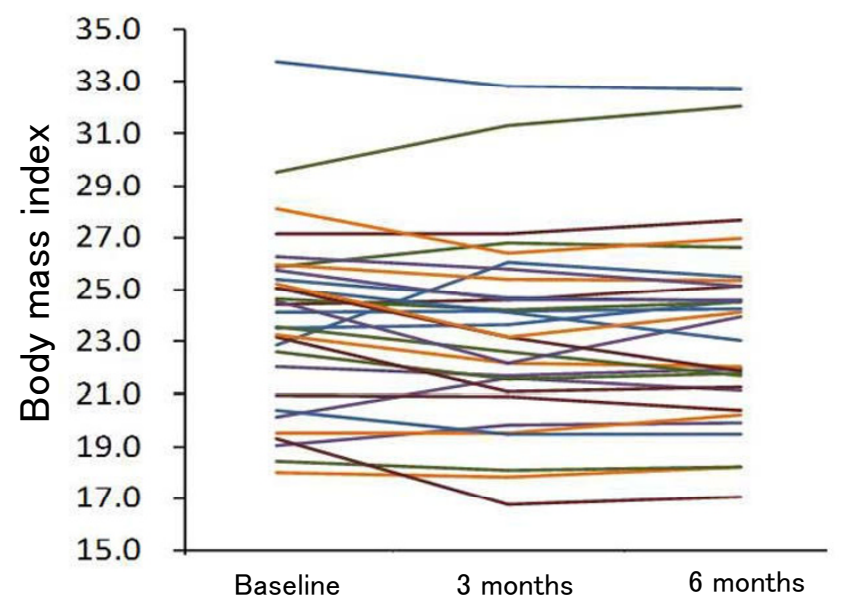

Figure 2

Individual changes in body mass index over 6 months $(\mathbf{n}=\mathbf{3 3})$. Two drop-out patients were included. 


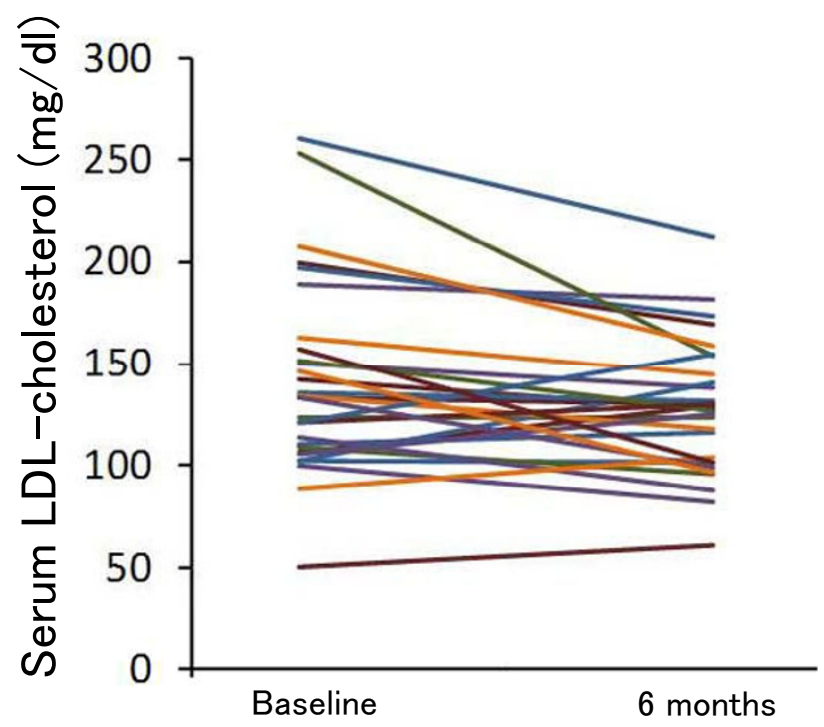

Figure 3

Individual changes in serum LDL-cholesterol concentrations over 6 months $(n=29)$. Four patients were excluded because they received lipid-lowering drugs.

low attrition rate of $6 \%$ over 6 months. Beyond calorie restriction, CRD has an advantage in comparison to HCDs, in that dietary fat and protein have little effect on postprandial blood glucose levels, while dietary carbohydrate is a major stimulus $[3,4]$.

The attrition rate for CRD was lower than that in other studies on CRDs (22\% for 3 months, and 45\%, 33\% and

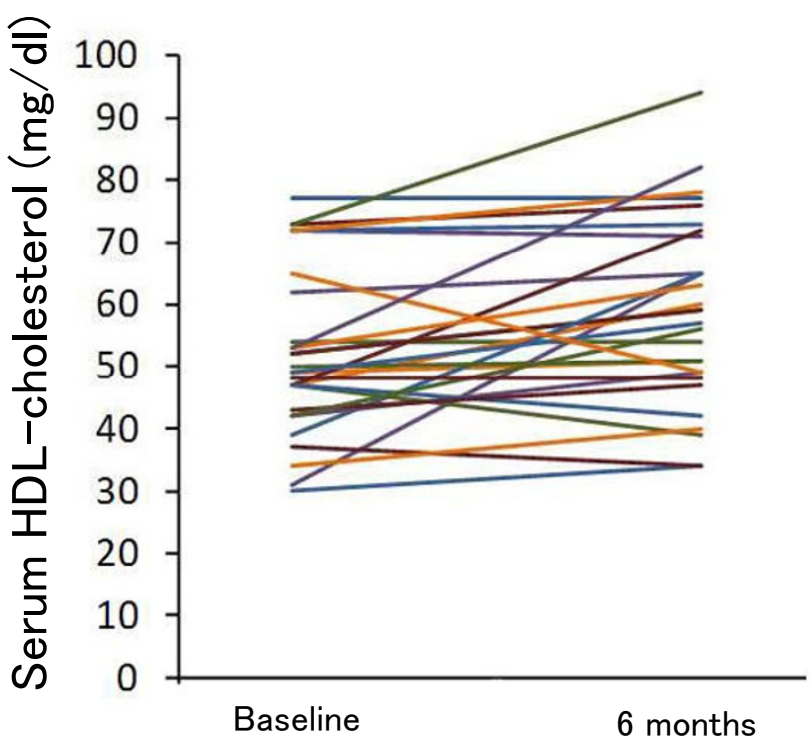

Figure 4

Individual changes in serum HDL-cholesterol concentrations over 6 months $(n=29)$. Four patients were excluded because they received lipid-lowering drugs.

$27 \%$ for 6 months) $[7,12-14]$. It should also be noted that the attrition rate in the previous study on CRD was lower in the first year ( $8 \%$ ) but higher in the second year $(33 \%)$ [8]. This is probably due to reduced motivation because of the improvement of glycemic control during the first year.

In conclusion, the 30\%-carbohydrate diet led to a remarkable reduction in HbA1c levels from baseline to 6 months,

Table 4: Changes in HbAlc, BMI, serum lipids and creatinine, blood pressure and dose of antidiabetic drugs $(n=33)$

\begin{tabular}{|c|c|c|c|c|}
\hline & Baseline & After 3 months & After 6 months & $P$ \\
\hline HbAlc (\%) & $10.9 \pm 1.6(9.0-14.4)$ & $7.8 \pm 1.5(5.9-\mid \mathrm{I} .3)$ & $7.4 \pm 1.4(5.5-12.7)$ & $<0.001$ \\
\hline BMI & $23.8 \pm 3.3(18.0-33.8)$ & $23.5 \pm 3.4(16.8-32.8)$ & $23.5 \pm 3.4(17.1-32.7)$ & 0.057 \\
\hline Serum LDL-cholesterol (mg/dl)* & $\mid 42 \pm 50(5 \mid-260)$ & & $128 \pm 34(6 \mid-213)$ & 0.036 \\
\hline Serum HDL-cholesterol (mg/dl)* & $52 \pm 14(30-77)$ & & $59 \pm 16(34-94)$ & 0.008 \\
\hline Serum triglyceride $(\mathrm{mg} / \mathrm{dl})^{*}$ & $182 \pm 189(50-823)$ & & $157 \pm 178(34-721)$ & 0.39 \\
\hline Serum creatinine $(\mathrm{mg} / \mathrm{dl})$ & $0.68 \pm 0.20(0.38-1.20)$ & & $0.71 \pm 0.21(0.44-1.25)$ & 0.21 \\
\hline Systolic BP $(\mathrm{mmHg})$ & $138 \pm 17(104-175)$ & & $135 \pm 14(97-157)$ & 0.24 \\
\hline Diastolic BP (mmHg) & $81 \pm 11(59-102)$ & & $81 \pm 11(48-113)$ & 0.64 \\
\hline \multicolumn{5}{|l|}{ Patients with antidiabetic drugs (n) } \\
\hline Glibenclamide & $\mathrm{n}=6(4.0 \mathrm{mg})$ & $\mathrm{n}=3(\mathrm{l} .7 \mathrm{mg})$ & $\mathrm{n}=\mathrm{I}(2.5 \mathrm{mg})$ & \\
\hline Glimepiride & $\mathrm{n}=\mathrm{I}(3.0 \mathrm{mg})$ & $\mathrm{n}=2(0.75 \mathrm{mg})$ & $\mathrm{n}=0(0 \mathrm{mg})$ & \\
\hline Tolbutamide & $\mathrm{n}=0(0 \mathrm{mg})$ & $\mathrm{n}=0(0 \mathrm{mg})$ & $\mathrm{n}=\mathrm{I}(500 \mathrm{mg})$ & \\
\hline Metformin & $\mathrm{n}=0(0 \mathrm{mg})$ & $\mathrm{n}=2(500 \mathrm{mg})$ & $\mathrm{n}=5(600 \mathrm{mg})$ & \\
\hline Nateglinide & $\mathrm{n}=2(135 \mathrm{mg})$ & $\mathrm{n}=2(180 \mathrm{mg})$ & $\mathrm{n}=0(0 \mathrm{mg})$ & \\
\hline Pioglitazone & $\mathrm{n}=0(0 \mathrm{mg})$ & $\mathrm{n}=0(0 \mathrm{mg})$ & $\mathrm{n}=2(30 \mathrm{mg})$ & \\
\hline Miglitol & $\mathrm{n}=\mathrm{I}(150 \mathrm{mg})$ & $\mathrm{n}=3(100 \mathrm{mg})$ & $\mathrm{n}=7(125 \mathrm{mg})$ & \\
\hline
\end{tabular}

HbAlc: hemoglobin Alc; BMI: body mass index; BP: blood pressure. Values are means \pm SD. The numbers in parenthesis in HbAIc, BMI, serum lipids, serum creatinine and blood pressure indicate ranges, and those in antidiabetic drugs show a mean daily dose. Two drop-out patients are included in the analysis.

*: Four patients are excluded from serum lipids analysis because they received lipid-lowering drugs. 
together with improvement of serum cholesterol levels without any insulin therapy, hospital care or reinforcement of sulfonylureas, even among outpatients with severe T2DM. The effectiveness of the diet may be comparable to that of insulin therapy. CRD could be implemented with good compliance among outpatients; therefore, it can be an alternative to HCDs in the dietary management of T2DM.

\section{Abbreviations}

BMI: Body mass index; CRDs: Carbohydrate-restricted diets; CRD: Carbohydrate-reduced diet; HbA1c: Hemoglobin A1c; HCD: High-carbohydrate diet; T2DM: Type 2 diabetes.

\section{Competing interests}

The authors declare that they have no competing interests.

\section{Authors' contributions}

$\mathrm{HH}$ and TS designed the study and participated in data collection. HH, KW and HU performed statistical analysis and interpretation. $\mathrm{HH}$ wrote the manuscript.

\section{References}

I. Westman EC, Feinman RD, Mavropoulos JC, Vernon MC, Volek JS, Wortman JA, Yancy WS Jr, Phinney SD: Low-carbohydrate nutrition and metabolism. Am J Clin Nutr 2007, 86(2):276-284.

2. Accurso A, Bernstein RK, Dahlqvist A, Draznin B, Feinman RD, Fine EJ, Gleed A, Jacobs DB, Larson G, Lustig RH, et al.: Dietary carbohydrate restriction in type 2 diabetes mellitus and metabolic syndrome: time for a critical appraisal. Nutr Metab 2008, 5:9-16.

3. Gannon MC, Nuttall FQ: Effect of a high-protein, low-carbohydrate diet on blood glucose control in people with type 2 diabetes. Diabetes 2004, 53(9):2375-2382.

4. Boden G, Sargrad K, Homko C, Mozzoli M, Stein TP: Effect of a lowcarbohydrate diet on appetite, blood glucose levels, and insulin resistance in obese patients with type 2 diabetes. Ann Intern Med 2005, I 42(2):403-4I I.

5. Nielsen JV, Joensson E: Low-carbohydrate diet in type 2 diabetes: Stable improvement of bodyweight and glycemic control during 22 months follow-up. Nutr Metab (Lond). 2006, 3:22-26.

6. Dashti HM, Mathew TC, Khadada M, Al-Mousawi M, Talib H, Asfar SK, Behbahani Al, Al-Zaid NS: Beneficial effects of ketogenic diet in obese diabetic subjects. Mol Cell Biochem 2007, 302(2):249-256.

7. Westman EC, Yancy WS, Mavropoulos JC, Marquart M, McDuffie JR: The effect of a low-carbohydrate, ketogenic diet versus a low-glycemic index diet on glycemic control in type 2 diabetes mellitus. Nutr Metab (Lond). 2008, 5:36-44.

8. Haimoto $\mathrm{H}$, Iwata $M$, Wakai $\mathrm{K}$, Umegaki $\mathrm{H}$ : Long-term effects of a diet loosely restricting carbohydrates on HbAlc levels, BMI and tapering of sulfonylureas in type 2 diabetes: A 2-year follow-up study. Diabetes Res Clin Pract. 2008, 79(2):350-356.

9. Tanaka K, Moriya T, Kanamori A, Yajima Y: Analysis and a longterm follow up of ketosis-onset Japanese NIDDM patients. Diabetes Res Clin Pract. 1999, 44(2): I 37-I 46.

10. Nathan DM, Buse JB, Davidson MB, Heine RJ, Holman RR, Sherwin R, Zinman B: Management of hyperglycemia in type 2 diabetes: $A$ consensus algorithm for the initiation and adjustment of therapy: A consensus statement from the American Diabetes Association and the European Association for the Study of Diabetes. Diabetes Care 2006, 29(9): 1963-1972.

II. Kobayashi M, Yamazaki K, Hirao K, Oishi M, Kanatsuka A, Yamauchi M, Takagi H, Kawai K: Diabetes Clinical Data Management Study Group, The status of diabetes control and antidiabetic drug therapy in Japan-A cross-sectional survey of 17,000 patients with diabetes mellitus (JDDM I). Diabet Res Clin Pract 2006, 73(2): 198-204.

12. Daly ME, Paisey R, Paisey R, Millward BA, Eccles C, Williams K, Hammersley S, Macleod KM, Gale TJ: Short-term effects of severe dietary carbohydrate-restriction advice in Type 2 diabetes a randomized controlled trial. Diabet Med 2006, 23(I):15-20.

13. Foster GD, Wyatt HR, Hill JO, McGuckin BG, Brill C, Mohammed BS, Szapary PO, Rader DJ, Edman JS, Klein S: A randomized trial of a low-carbohydrate diet for obesity. N Engl J Med 2003, 348(2I):2082-2090.

14. Samaha FF, Iqbal N, Seshadri P, Chicano KL, Daily DA, McGrory J, Williams T, Williams M, Gracely EJ, Stern L: A low-carbohydrate as compared with a low-fat diet in severe obesity. N Engl J Med 2003, 348(2I):2074-208I.
Publish with Biomed Central and every scientist can read your work free of charge

"BioMed Central will be the most significant development for disseminating the results of biomedical research in our lifetime. "

Sir Paul Nurse, Cancer Research UK

Your research papers will be:

- available free of charge to the entire biomedical community

- peer reviewed and published immediately upon acceptance

- cited in PubMed and archived on PubMed Central

- yours - you keep the copyright 